\title{
BMJ Open Differences among primary care patients with different mechanical patterns of low back pain: a cross-sectional investigation
}

\author{
Lauren S Della Mora, ${ }^{1}$ Anthony V Perruccio, ${ }^{1,2,3,4}$ Elizabeth M Badley, ${ }^{1,2,3}$ \\ Y Raja Rampersaud ${ }^{3,4}$
}

To cite: Della Mora LS, Perruccio AV, Badley EM, et al. Differences among primary care patients with different mechanical patterns of low back pain: a cross-sectional investigation. BMJ Open 2016;6:e13060 doi:10.1136/bmjopen-2016013060

- Prepublication history for this paper is available online. To view these files please visit the journal online (http://dx.doi.org/10.1136/ bmjopen-2016-013060).

Received 22 June 2016 Revised 2 November 2016 Accepted 15 November 2016

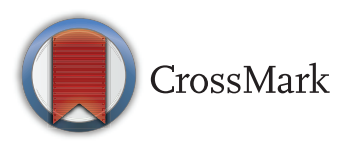

\footnotetext{
${ }^{1}$ Dalla Lana School of Public Health, University of Toronto, Toronto, Ontario, Canada ${ }^{2}$ Health Care and Outcomes Research, Krembil Research Institute, University Health Network, Toronto, Ontario, Canada

${ }^{3}$ Arthritis Program, University Health Network, Toronto, Ontario, Canada

${ }^{4}$ Faculty of Medicine Department of Surgery, University of Toronto, Toronto, Ontario, Canada
}

Correspondence to Dr Y Raja Rampersaud; raja.rampersaud@uhn.ca

\section{ABSTRACT \\ Objectives: To characterise and compare a persistent low back pain (LBP) population based on 4 clinical pain patterns. \\ Design: Cross-sectional analysis of patient-reported data. \\ Setting: Patients from 220 primary care practitioners in 3 cities in Ontario, Canada. \\ Participants: 1020 individuals seeking LBP care. Inclusion criteria: LBP symptoms lasting 11/2- 12 months, or unmanageable recurrent symptoms; ages 18+years. Exclusion criteria: pregnant/1-year postpartum; involved in active litigation or motor vehicle injury; emergent spinal presentations; pain disorder diagnosis; work injury claim; or constant symptoms persisting >12 months postonset.}

Main outcome measure: Hall pain pattern subgroups: back dominant pain aggravated by flexion (P1) or extension (P2), or leg dominant constant (P3) or intermittent (P4) pain (multinomial logistic outcome; referent: P1).

Results: Groups P1 and P2 had the highest proportion of women. P2 and P4 had higher mean ages and comorbidity counts. P3 and P4 had higher proportions of overweight/obese individuals and lower general health scores. Adjusted models: being male and overweight/obese was associated with increased odds of being in P3 (OR 1.64 (95\% Cl 1.10 to 2.46 ), and OR 1.74 (1.13 to 2.68), respectively) and P4 (OR 1.87 (1.11 to 3.15 ) and OR 1.91 (1.06 to 3.42), respectively), and increasing age with increased odds of being in P2 (OR 1.02 (1.01 to 1.03)) and P4 (OR 1.06 (1.04 to 1.08$)$ ). Increasing comorbidity count was associated with increased odds of being in P2 (OR 1.14 (1.0 to 1.3)), and better general health scores with decreased odds of being in P3 (OR 0.40 (0.18 to 0.93)).

Conclusions: This is the first study to examine the 'Hall system' in a non-rehab primary care population. Subgroups classified according to this system appear to have distinct profiles. Further research is needed to better characterise and determine the prognostic implication of these clinically derived subgroups.

\section{Strengths and limitations of this study}

- The large sample size and rich data set provide a basis on which research on the mechanical subgrouping of the low back pain (LBP) population can be advanced.

- The study population likely represents the general LBP population seeking primary care in Ontario and Canada more generally.

- Potential for selection bias as only primary care practitioners who volunteered to participate in the Inter-professional Spine Assessment and Education Clinics (ISAEC) programme were able to refer patients to the programme.

- The profile of patients seeking and having access to primary care for LBP through Canada's universal publicly funded healthcare system may differ from those in jurisdictions operating under different healthcare funding regimes.

\section{INTRODUCTION}

Low back pain (LBP) is a condition of global concern. ${ }^{1}$ It is the most common cause of years lived with disability ${ }^{1}$ and one of the leading reasons for seeking primary healthcare $^{2-5}$ Estimates suggest that up to $9 \%$ of the world's population has LBP at any given time, ${ }^{1}$ and population-based studies report that $60-90 \%$ of adults will experience LBP at some point in their lifetime. ${ }^{6-8}$ Unfortunately, the prevalence and burden of LBP continue to increase. ${ }^{9-11}$ LBP is not only a burden for individuals, many of whom will experience disabling and persistent symptoms, but the associated healthcare costs and productivity losses have significant socioeconomic impacts on society as well. ${ }^{12-16}$

Eighty to ninety per cent of chronic LBP cases presenting to primary care are considered 'non-specific', without a known cause or readily identifiable pathology. ${ }^{17} 18$ Often, acute and chronic LBP is managed in the 
primary care setting as a homogeneous condition with a 'one size fits all' approach. ${ }^{19-21}$ Yet, it is well known that individuals with LBP can have a wide range of aetiologies and symptom profiles, and researchers have suggested LBP classifications based on diagnosis, prognosis or treatment $^{22}$ in an attempt to derive more homogeneous subgroups. Identifying such subgroups has been a top priority at the International Forums for Low Back Pain Research in Primary Care since the mid-1990s. ${ }^{23-25}$ Kent and Keating ${ }^{26}$ suggest that subgrouping is an intuitive approach as many clinicians do not perceive LBP as a single condition, believing it is possible to recognise different subgroups. Identifying distinct characteristics between any proposed LBP subgroups would support the ability of primary care to provide tailored, subgroupspecific treatment approaches to optimise outcomes. ${ }^{27-29}$ Further, identifying unique subgroup characteristics would warrant additional epidemiological investigation within the LBP population with an aim of determining potentially subgroup-specific risk factors, aetiologies and/or outcomes.

In Canada, Hall et $a l^{27}$ demonstrated the value of subgrouping when they identified that patients who received treatment based on their classification into one of four patterns $(\mathrm{P})$ of mechanical LBP (summarised as back dominant pain, ie, flexion (P1) vs extension (P2) aggravated, and constant (P3) vs intermittent (P4) leg dominant pain) reported reduced pain and medication use post-treatment as compared with patients who did not receive stratified care. This system was developed and used principally for patients with LBP being managed by a physiotherapist, but has recently been adopted for primary care provider (family physicians and nurse practitioners) clinical use and education in three different provinces in Canada: Saskatchewan, British Columbia and Ontario. ${ }^{30-32}$ The 'Hall system' allows for a simple and practical starting point for primary care providers to subgroup acute-to-chronic LBP and thus enable initial stratified patient management recommendations based on repetitive pain relieving directional exercise and modified activity. ${ }^{33}$

The objective of this study was to assess, in a primary care cohort of patients with LBP, whether the four subgroups of the Hall LBP classification system ${ }^{27}$ demonstrate any distinct demographic and health characteristics.

\section{METHODS}

\section{Data source}

Study data were collected in clinic as part of the Inter-professional Spine Assessment and Education Clinics (ISAEC) pilot programme (http://www.isaec. org); a programme funded by the provincial Ontario Ministry of Health and Long Term Care. The purpose of ISAEC was to identify patients who reported persistent (6-52 weeks) or recurrent LBP (regardless of duration) presenting to their primary care provider (physicians and nurse practitioners), and to use an interdisciplinary shared-care model to provide timely stratified education and self-management recommendations. Two hundred and twenty primary care providers based out of three cities in Ontario, Canada (namely Toronto, Hamilton and Thunder Bay) participated in the programme and referred patients to an ISAEC clinic. This study analysed data collected from consecutive ISAEC patients between November 2012 and February 2014.

To be eligible for the ISAEC pilot programme, patients had to be 18 years of age or older and experiencing LBP-related symptoms that were either persistent, lasting from 6 weeks to 12 months, or recurring (regardless of duration). Persistent pain was defined as constant daily pain of varying intensity and recurrent pain was defined as episodic pain with a current episode no longer manageable by primary care measures compared with previous episodes. The lower time limit excluded patients experiencing acute LBP that had a favourable natural history, while the upper time limit excluded patients with persistent pain (as per our working definition) in excess of 1 year in duration. ${ }^{34}$ The principle focus of the ISAEC programme is education and enabling patient and primary care providers to use chronic disease selfmanagement principles to manage their LBP and mitigate chronicity. Patients were ineligible if they had a work-based insurance claim, were in pain following a motor vehicle accident, had established narcotic dependency (ie, those actively being managed by a pain specialist), were involved in active litigation, were pregnant/postpartum $(<1$ year), had emergent spinal presentations or had an established diagnosis of a pain disorder.

\section{LBP classification}

The subgrouping of patients with LBP with mechanical 'non-specific' symptoms was based on the classification system proposed by Hall et al. ${ }^{27}$ The system relies on patient history and physical examination. A trained advanced practice clinician (APC) assessed patients. The dominant symptoms were classified by the APCs into one of four pain pattern subgroups: back dominant pain aggravated by flexion (P1), back dominant pain aggravated by extension (P2), constant leg dominant pain (P3) and intermittent leg dominant pain (P4). When applied by physiotherapists, inter-rater reliability for this system has been reported at $79 \% \quad(\kappa=0.61) .{ }^{35}$ Half of the ISAEC APCs were physiotherapists and the other half chiropractors. All APCs underwent a 13-week hands-on training curriculum (one full day per week) to ensure that the clinicians participating in the ISAEC programme had the appropriate interprofessional training to understand the full continuum of LBP assessment and care from the context of primary and specialty care. This included education in the clinics of spine surgeons, a physiatrist, a rheumatologist, primary care doctors and a pain psychologist; interprofessional best practice education sessions; and a final examination that included assessment of the APCs ability to effectively use the Hall classification system and the ISAEC management protocols. 


\section{Questionnaire data}

Patients attending ISAEC completed an intake questionnaire prior to consulting with a member of the ISAEC clinical team. All responses were self-reported. Patients reported their current age (years), sex, and height and weight, from which body mass index (BMI; $\mathrm{kg} / \mathrm{m}^{2}$ ) was calculated. Individuals were categorised as normal $(\mathrm{BMI}<24.99), \quad$ overweight $\quad(25 \leq \mathrm{BMI}<29.99) \quad$ or $\quad$ obese $(\mathrm{BMI} \geq 30)$.

Prevalent comorbidities were elicited using the SelfAdministered Comorbidity Questionnaire, ${ }^{36}$ whereby patients were presented with a list of conditions (high cholesterol; high blood pressure; cardiovascular disease (stroke; heart disease/coronary artery disease; peripheral vascular disease); asthma/chronic obstructive pulmonary disease; diabetes; ulcer or stomach disease; cancer; depression; anxiety, bipolar disorder, obsessive compulsive disorder and panic disorder; osteoarthritis; rheumatoid arthritis) with a request to indicate all that were applicable. A comorbidity count was derived.

Patients indicated whether or not they had a history of back problems (yes, no).

Disability was assessed with the Oswestry Disability Index, a widely used and validated, spine-specific disability measure for patients with LBP $^{37-40}$ The measure includes 10 items that assess pain intensity and interference with general movement, personal care, sleeping, social life, travelling and work. Patients respond to each item using a $0-5$ scale. The sum of the 10 scores is reported as a percentage of the total possible score (maximum of 50) with higher percentages indicating greater disability.

The EuroQol-5D, a generic, validated questionnaire, was used to assess overall health-related quality of life. ${ }^{41} 42$ The questionnaire elicits level of severity, rated 1 (no problems), 2 (some/moderate problems) or 3 (extreme problems), for each of five health dimensions: mobility, self-care, daily activities, pain/discomfort and anxiety/ depression. A summary score is generated by applying published weights to each of the 243 possible health states. ${ }^{43}$ A value-adjusted summary score of 100 indicates that, on the day that the questionnaire was completed, the patient had no problems on any of the five items, while lower value-adjusted summary scores indicate some degree of problems and poorer self-rated health.

\section{Statistical analyses}

Descriptive statistics were generated for each of the study measures by clinical LBP pattern subgroup: mean and SD were calculated for age, BMI, number of chronic conditions, Oswestry per cent disability and EuroQol-5D summary score, and proportions for sex, age groups, BMI categories and history of back problems. Statistical comparisons across subgroups were made by way of analysis of variance (age, BMI, number of chronic conditions, Oswestry per cent disability and EuroQol-5D summary score), Fisher's exact test (age group) and $\chi^{2}$ test (sex, BMI category and history of back problems).
An adjusted multinomial regression analysis was undertaken to identify factors associated with clinical pain pattern subgroups. The focus was on identifying non-back-specific factors which potentially distinguished between back pain pattern subgroups. The factors included demographic (age and sex) and health characteristics (overweight/obese vs normal, number of chronic conditions and EuroQol-5D summary score). The four clinical LBP subgroups constituted the model outcome with 'back pain aggravated by flexion' (P1) used as the referent category; P1 was chosen as it was the largest subgroup.

Statistical analyses were conducted using RStudio software (V.0.98.507, RStudio, Boston, Massachusetts, USA). Statistical probability levels $\leq 0.05$ were deemed as statistically significant.

\section{Patient involvement}

Patient engagement was not elicited for this specific study. However, active patient engagement in the form of focus groups preimplementation and postimplementation of the ISAEC pilot programme has been an integral part of the development and ongoing improvement of the ISAEC programme.

\section{RESULTS}

During the study time period, 1197 patients were referred to an ISAEC clinic; 64 of these were subsequently deemed ineligible for the programme. Data were available for 970 patients $(85.6 \%)$ for this study (figure 1). The mean age of the sample was 50 years (SD 15.7); $56 \%$ were women. By pain pattern subgroup, 405 patients were categorised as P1 (42\%), $301(31 \%)$ as P2, $164(17 \%)$ as P3 and $100(10 \%)$ as P4.

Descriptive statistics for the sample are presented in table 1 by pain pattern subgroup. Overall, ages ranged from 18 to 93 years, with mean subgroup-specific ages ranging from 46 to 63 years. Statistically significant differences between at least one subgroup and the others were observed for several factors. The P2 and P4 groups had a higher proportion of older individuals, while the proportion of women was higher in the P1 and P2 groups.

Significant differences in BMI were found, with the P2 and $\mathrm{P} 4$ groups having higher proportions of obese individuals. The P2 and P4 groups also had higher mean comorbidity counts. Finally, the P3 group had the highest (ie, worse) mean Oswestry Disability Index scores and lowest overall health-related quality of life scores.

Considering age, sex, BMI, the number of comorbidities and general health status scores, results from the multinomial logistic regression analysis suggest distinct features between LBP subgroups (table 2). Increasing age was associated with increased odds of being in the P2 (OR 1.02 (95\% CI 1.01 to 1.03)) and P4 groups (OR 1.06 (95\% CI 1.04 to 1.08$)$ ), relative to the P1 group. 
Figure 1 Patient flow diagram. ISAEC, Inter-professional Spine Assessment and Education Clinics.

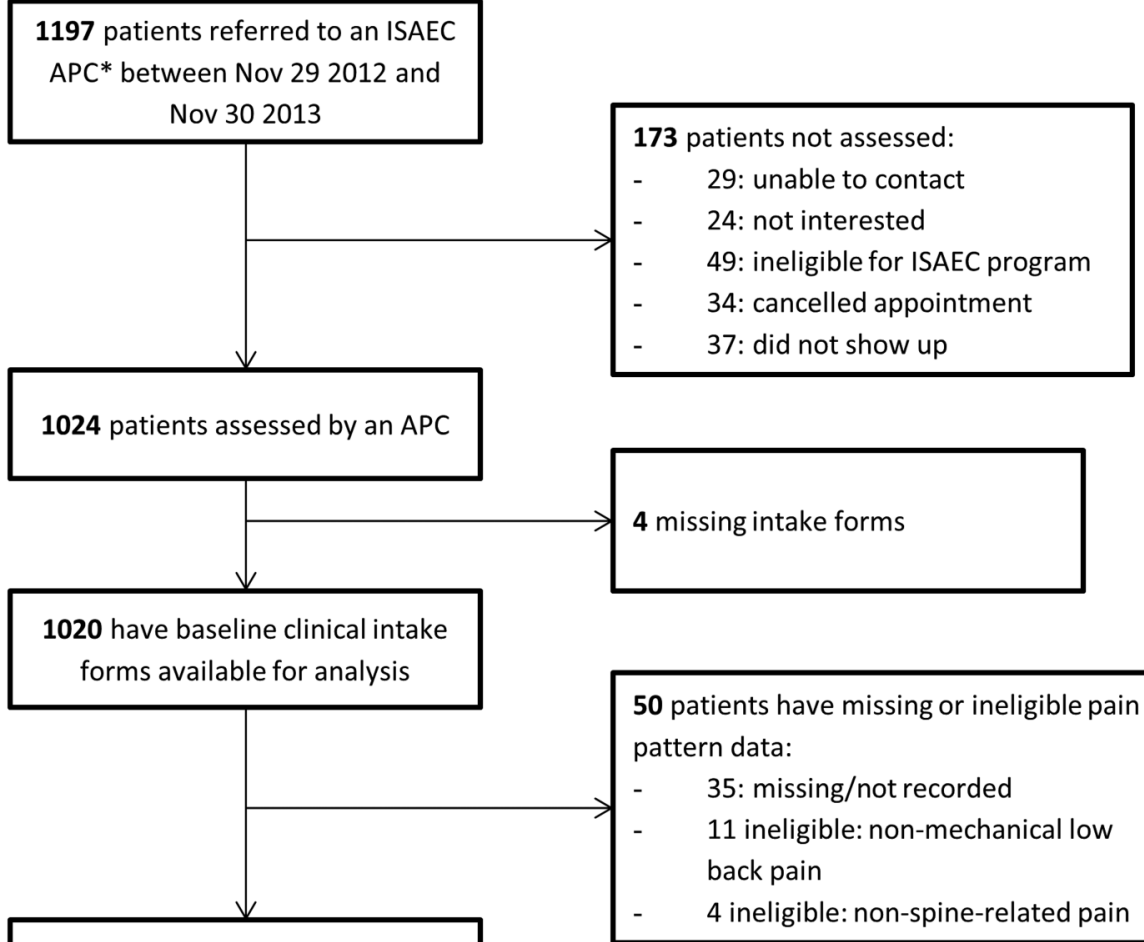

\section{Analysis sample: $\mathbf{9 7 0}$ have valid}

pain pattern data (P1 to $\mathrm{P} 4)$

*APC: Advanced-practice clinician
Being male was associated with increased odds of being in the P3 (OR 1.64 (95\% CI 1.1 to 2.46)) and P4 groups (OR 1.87 (95\% CI 1.11 to 3.15)). Compared with those with normal BMI, overweight/obese individuals had increased odds of being in the P3 group (OR 1.74 (95\% CI 1.13 to 2.68)) and P4 group (OR 1.91 (95\% CI 1.06 to 3.42)). Increasing number of chronic conditions was associated with increased odds of being in the P2 group (OR 1.14 (95\% CI 1.00 to 1.30)). Finally, higher EuroQol-5D score (ie, better health) was associated with decreased odds of being in the P3 group (OR 0.40 (95\% CI 0.18 to 0.93$)$ ).

\section{DISCUSSION}

This study is the first to assess the discriminatory ability of the Hall mechanical LBP classification system in a non-rehabilitation primary care setting. Among patients assessed in the ISAEC shared-care primary care network, we found differences in demographic and specific health characteristics between subgroups classified according to dominant LBP patterns as described by Hall et $_{\text {al. }}{ }^{27}$ Differences persisted following adjusted analysis, in which we identified unique and independent associations with age, sex, BMI, number of chronic conditions and self-rated health status.

The most clinically distinct observations were that increasing age and number of comorbidities were associated with the back pain with extension (P2) and/or intermittent leg pain (P4) groups. For every 1 year increase in age, the odds increased by $2 \%$ and $6 \%$ for P2 and P4, representing a $22 \%$ and $79 \%$, respectively, increased odds for each decade of age. Every unit increase in comorbidity count increased the odds of being in $\mathrm{P} 2$ by $14 \%$. Patients in $\mathrm{P} 2$ and $\mathrm{P} 4$ present with mechanical symptom patterns which, in the absence of other symptoms or signs to suggest red flags (ie, tumour, infection or fracture), represent symptomatic spine osteoarthritis (ie, extension dominant symptom provocation) that are typical of symptoms of lumbar spinal stenosis (ie, back pain and/or neurogenic claudication) which is due to facet osteoarthritic changes and posterior spinal element loading in extension. ${ }^{44-47}$ Studies have identified that increasing age $\mathrm{e}^{4-52}$ and number of comorbidities $^{53-55}$ are generally associated with osteoarthritis. Our findings indicate that men were more likely to present with leg dominant symptoms than women. While the female sex is a known risk factor for osteoarthritis of the hand, hip and knee, ${ }^{50525657}$ the association with lumbar spine osteoarthritis is not as clear, ${ }^{45}{ }^{57-59}$ and there is mixed evidence regarding the association between facet joint osteoarthritis and back pain. ${ }^{49516061}$ It is noted by Hall et al that $\mathrm{P} 4$ represents the clinical syndrome of neurogenic claudication. However, they did not speculate on the pathoanatomic aetiology of P2 and also note that their classification by dominant pain pattern is not designed to make inference to a pathoanatomical source of pain. ${ }^{27}$ Whether 
Table 1 Demographic factors and health measures describing the study population stratified by pain pattern subgroup

\begin{tabular}{|c|c|c|c|c|c|}
\hline & \multicolumn{4}{|c|}{ LBP subgroups based on clinical presentation $(n=970)$} & \multirow[b]{2}{*}{ p Value* } \\
\hline & $\begin{array}{l}\text { Back dominant pain aggravated } \\
\text { by flexion (P1) ( }=405 ; 42 \%)\end{array}$ & $\begin{array}{l}\text { Back dominant pain aggravated } \\
\text { by extension (P2) (n=301; 31\%) }\end{array}$ & $\begin{array}{l}\text { Constant leg dominant } \\
\text { pain }(P 3)(n=164 ; 17 \%)\end{array}$ & $\begin{array}{l}\text { Intermittent leg dominant } \\
\text { pain }(P 4)(n=100 ; 10 \%)\end{array}$ & \\
\hline \multicolumn{6}{|l|}{ Demographic factors } \\
\hline Sex (\% female) & 59 & 61 & 46 & 46 & 0.001 \\
\hline Mean age (range) & $\begin{array}{l}46.2 \pm 14.4 \\
(18-85)\end{array}$ & $\begin{array}{l}51.6 \pm 16.6 \\
(18-93)\end{array}$ & $47.4 \pm 13.3,(19-85)$ & $\begin{array}{l}62.9 \pm 14.1 \\
(31-92)\end{array}$ & $<0.001$ \\
\hline Age groups (\%) & & & & & $<0.001$ \\
\hline $18-29$ & 14 & 11 & 7 & 0 & \\
\hline 30-39 & 23 & 16 & 24 & 6 & \\
\hline 40-49 & 24 & 18 & 29 & 12 & \\
\hline $50-59$ & 20 & 21 & 21 & 22 & \\
\hline $60+$ & 20 & 34 & 20 & 60 & \\
\hline $\begin{array}{l}\text { Mean body mass index } \\
\left(\mathrm{kg} / \mathrm{m}^{2}\right)\end{array}$ & $26.4 \pm 5.5$ & $27.6 \pm 6.3$ & $28.1 \pm 6.0$ & $28.4 \pm 5.5$ & $<0.001$ \\
\hline $\begin{array}{l}\text { Body mass index } \\
\text { categories }(\%)\end{array}$ & & & & & 0.004 \\
\hline Normal weight $(<25)$ & 47 & 41 & 32 & 24 & \\
\hline Overweight (25-29.9) & 33 & 30 & 41 & 46 & \\
\hline Obese $(\geq 30)$ & 20 & 29 & 27 & 31 & \\
\hline \multicolumn{6}{|l|}{ Health measures } \\
\hline $\begin{array}{l}\text { Mean number of } \\
\text { chronic conditions } \\
\text { (range) }\end{array}$ & $1.0 \pm 1.3(0-11)$ & $1.4 \pm 1.5(0-10)$ & $1.0 \pm 1.3(0-5)$ & $1.9 \pm 1.8(0-7)$ & $<0.001$ \\
\hline $\begin{array}{l}\text { History of back } \\
\text { problems (\% yes) }\end{array}$ & 58 & 50 & 59 & 59 & 0.141 \\
\hline $\begin{array}{l}\text { Mean Oswestry per } \\
\text { cent disability } †\end{array}$ & $33.3 \pm 17.2$ & $33.7 \pm 17.7$ & $44.4 \pm 19.1$ & $38.2 \pm 17.8$ & $<0.001$ \\
\hline $\begin{array}{l}\text { Mean EuroQol-5D } \\
\text { summary score } \ddagger\end{array}$ & $66.0 \pm 21.4$ & $65.5 \pm 20.3$ & $56.9 \pm 22.7$ & $61.6 \pm 20.0$ & $<0.001$ \\
\hline $\begin{array}{l}\text { Data presented as mean } \pm S I \\
{ }^{*} p \text { Value for } \chi^{2} \text {, analysis of } v \\
\dagger \text { thigher percentage indicate } \\
\neq \text { tScores decreasing from } 10 \\
\text { LBP, low back pain. }\end{array}$ & $\begin{array}{l}\text { here indicated. } \\
\text { ance or Fisher's exact test where appro } \\
\text { reater disability. } \\
\text { idicate poorer health-related quality of }\end{array}$ & $\begin{array}{l}\text { riate. } \\
\text { e. }\end{array}$ & & & \\
\hline
\end{tabular}


Table 2 Multinomial logistic regression results; outcome: pain pattern subgroup*

\begin{tabular}{|c|c|c|c|c|}
\hline Factor & Subgroup & OR & $95 \% \mathrm{Cl}$ & p Value \\
\hline \multicolumn{5}{|l|}{ Age (years) } \\
\hline & Back extension & 1.02 & 1.01 to 1.03 & 0.002 \\
\hline & Constant leg & 1.00 & 0.99 to 1.02 & 0.626 \\
\hline & Intermittent leg & 1.06 & 1.04 to 1.08 & $<0.001$ \\
\hline \multicolumn{5}{|l|}{ Sex } \\
\hline \multirow[t]{3}{*}{ Male (Ref: female) } & Back extension & 0.90 & 0.64 to 1.27 & 0.551 \\
\hline & Constant leg & 1.64 & 1.10 to 2.46 & 0.017 \\
\hline & Intermittent leg & 1.87 & 1.11 to 3.15 & 0.018 \\
\hline \multicolumn{5}{|l|}{ Body mass index } \\
\hline \multirow[t]{3}{*}{ Overweight/obese (Ref: normal) } & Back extension & 1.19 & 0.84 to 1.68 & 0.322 \\
\hline & Constant leg & 1.74 & 1.13 to 2.68 & 0.012 \\
\hline & Intermittent leg & 1.91 & 1.06 to 3.42 & 0.031 \\
\hline \multicolumn{5}{|l|}{ Number of chronic conditions $†$} \\
\hline & Back extension & 1.14 & 1.00 to 1.30 & 0.045 \\
\hline & Constant leg & 0.93 & 0.78 to 1.10 & 0.400 \\
\hline & Intermittent leg & 1.13 & 0.95 to 1.34 & 0.186 \\
\hline \multicolumn{5}{|l|}{ EuroQol-5D summary score } \\
\hline & Back extension & 1.86 & 0.86 to 4.00 & 0.113 \\
\hline & Constant leg & 0.40 & 0.18 to 0.93 & 0.033 \\
\hline & Intermittent leg & 0.56 & 0.18 to 1.69 & 0.301 \\
\hline
\end{tabular}

*'Back flexion' is referent group.

†Comorbidity count developed based on those conditions with at least $5 \%$ prevalence in the sample (high cholesterol, high blood pressure, diabetes, depression, osteoarthritis, and asthma/chronic obstructive pulmonary disease).

our findings truly indicate a greater likelihood of an underlying osteoarthritis aetiology for the P2 and P4 groups would require advanced imaging and symptom correlation. However, this is likely to be a costly and unreliable exercise, given the well-known poor correlation of back symptoms and the pathoanatomical changes noted in spinal imaging. ${ }^{11}$ In fact, one of the mandates of the ISAEC programme is to reduce unnecessary imaging by using valid clinical tools to enable stratified care. Anecdotally, for those with P4 symptoms that went on to surgical assessment and imaging, the anatomical diagnosis of spinal stenosis was confirmed. Finally, our finding that P3 pain (constant leg pain, typically termed 'sciatica') was associated with worse self-rated health status is not surprising, given the typically severe degree of pain and disability associated with the clinical syndrome of radiculopathy. ${ }^{62}$

This study was based on a patient population drawn from three cities in different regions of Ontario, Canada and from the practices of 220 primary care practitioners. Thus, our sample likely represents the general chronic LBP population seeking primary care in Ontario, the most populous province in Canada, and likely Canada generally. However, only patients of primary care practitioners who volunteered to participate in the ISAEC programme were available to this study, which may have introduced an element of selection bias. Furthermore, Canadians have a universal publicly funded healthcare system and the profile of patients seeking and having access to primary care for LBP may differ from those in jurisdictions operating under different healthcare funding regimes. It is also worth noting that estimates of inter-rater reliability for the Hall classification system have been published for physiotherapists but not for chiropractors. This raises a limitation of this study since potential variability in how chiropractor APCs (half of all ISAEC APCs) applied the Hall classification system was not evaluated and cannot be inferred from other studies. Additionally, for cases where patients' reporting of pain dominance was ambiguous or the pattern was potentially mixed, the APCs rephrased the symptom questions in multiple iterations to establish which symptom or aggravating factor was most functionally limiting and therefore determined the dominant pattern. The prevalence of this uncommon scenario was not objectively captured. Nevertheless, our findings, based on a large primary care sample and rich data set, provide an important basis on which research in the subgrouping of the LBP population can be advanced. While findings specific to two of the four subgroups suggest a potentially greater likelihood of underlying osteoarthritis, an objective identification of spine osteoarthritis (ie, cross-sectional spinal imaging), or otherwise generalised osteoarthritis, was not documented.

Establishing the utility of any subgrouping system relies on a clear understanding and description of its intended purpose(s). In 2011, Fairbank $e t a t^{22}$ published a systematic review of LBP classification systems and identified a total of 28 systems that were either descriptive, prognostic or intended to guide treatment. In September 2014, the National Institutes for Health Task Force for Research Standards for Chronic Low Back Pain published a report recommending that chronic LBP be stratified based on impact, ${ }^{63}$ where impact was 
defined as a combined measure of pain intensity, functional status, and pain interference with normal activities. While this system may be useful for research purposes, the authors state that further investigation of the clinical utility of this stratification system is necessary. While the clinical utility of the system used for the present study has been reported for treatment purposes ${ }^{27}$ our work suggests that this system may facilitate research as well, particularly at identifying unique, more homogeneous subgroups, with the goal of elucidating aetiology and facilitating group-specific risk management. For example, in addition to directional exercise and activity modification as suggested by Hall et al, a clinical diagnosis of spinal osteoarthritis for P2 and P4 patients can also allow for more targeted medical management, such as more aggressive use of non-steroidal anti-inflammatory drugs, or more appropriate surgical referrals for patients with $\mathrm{P} 4$ without the need for advanced imaging. ${ }^{30} \quad 64 \quad 65$ This study has uniquely assessed the Hall system in a broader LBP population that, as noted above, is more representative of the primary care spectrum of chronic LBP. The study by Hall and colleagues evaluated a mixed group of patients assessed in an outpatient rehabilitation setting, suggesting that only patients with insurance coverage or the ability to self-pay were included, and thereby potentially introducing selection bias into the study. In contrast, our primary care cohort was situated within a universally funded health system. In the present study, older individuals were more likely to present with dominant symptoms consistent with the $\mathrm{P} 2$ and $\mathrm{P} 4$ pain patterns. Interestingly, these two groups comprised $31 \%$ and $10 \%$ of the current cohort, compared with $7.8 \%$ and $1.5 \%$, respectively, of patients enrolled in the study by Hall et $a .^{27}$ For the latter study, barriers, including socioeconomic, to rehabilitation/exercise in the older population $^{66}$ may explain some of the comparative discrepancy. We are not aware of any other studies that have evaluated other classification systems for distinct epidemiological profiles that may aid in further subgroup stratification.

The current primary care paradigm emphasises providing patient-focused, 'personalised' care, but also conserving limited health resources. Several existing classification systems involve complex criteria that cannot be quickly evaluated during a physician consultation, ${ }^{67}$ require expensive diagnostic tests or may not be feasible within the primary care setting. ${ }^{22}$ The classification system we adopted can be easily integrated in the clinical setting with good reliability since it has few and distinct categories that are simple to elicit from patients (ie, dominance and mechanical aspect of an individual's pain $)^{27}$ facilitating initial treatment decision-making for primary care practitioners with minimal added time and resource requirements. To the best of our knowledge, this is the largest study to describe the primary care seeking (medical doctor or nurse practitioner) persistent LBP population stratified by the proposed subgrouping system. It is the first study to identify unique patient and health characteristic correlates for these subgroups, with similar features in the P2 and P4 group suggestive of spinal osteoarthritis. Concluding similarly as have others, ${ }^{21}{ }^{23-25}$ a stratified approach to LBP, rather than the conventional non-specific approach, is supported for the clinical and research settings. For clinical and research purposes, a critical component of any classification system is the ability to differentiate between subclasses. For research, these pain pattern subgroupings may facilitate improved investigations of aetiology and identification of group-specific risk factors. Although not the focus of this paper, in other collaborative work by Alleyne et $a l,{ }^{33}$ we have noted ease of clinical translation of the Hall classification system to primary care providers with minimal training (online or in person session) and/or the use of a simple one page clinical tool (Clinically Organized Relevant Exam (CORE) Tool for the Low Back Pain). Clinically, subgroup-specific treatment based on this system has been shown to result in improved health outcomes, including fewer treatment days and significantly greater odds of no pain or medication use posttreatment compared with patients experiencing more homogeneous care. ${ }^{27}$ Randomised controlled trials comparing two alternate subgroup-specific treatment approaches to standard unstratified care for patients with acute/subacute or subacute/chronic LBP identified that subgroup-specific treatment was equally or more effective at reducing short-term and long-term disability. ${ }^{28} 6869$

Despite considerable investment in research and numerous clinical practice guidelines, the burden of LBP continues to increase. ${ }^{10} 11$ Recognising that the aetiology, course and/or outcomes of LBP can be highly variable, ${ }^{70-73}$ there is a critical need for an optimal disentanglement of this large clinical population. Ongoing optimisation of subgrouping distinct patient phenotypes with the potential to guide clinical management within the LBP population will have tremendous research and clinical impact. Our work suggests that stratification of LBP subgroups based on the aforementioned pain patterns appears viable and able to provide clinically relevant stratification in the primary care, non-rehabilitation LBP population. In addition, it provides a practical clinical starting point that can be easily added to subgrouping on the basis of chronicity risk ${ }^{28}$ and/or impact. ${ }^{63}$ Further, longitudinal comparative and prognostic evaluation work is required and has begun concurrently to this study.

Contributors AVP, EMB and YRR were involved in the conception/design of the study. LSDM and AVP drafted the plan for the data analyses. LSDM conducted data analysis. AVP and EMB provided statistical expertise. LSDM drafted the manuscript; and all authors were involved in interpretation of the results and revision of the manuscript and approved the final version of the manuscripts. YRR is the guarantor.

Funding The study was funded through the Minimal Access Ambulatory Spine Program Fund, University Health Network. 
Competing interests None declared.

Ethics approval University Health Network Research Ethics Board (\# 12-5477-BE and 14-7776-BE).

Provenance and peer review Not commissioned; externally peer reviewed.

Data sharing statement No additional data are available.

Open Access This is an Open Access article distributed in accordance with the Creative Commons Attribution Non Commercial (CC BY-NC 4.0) license, which permits others to distribute, remix, adapt, build upon this work noncommercially, and license their derivative works on different terms, provided the original work is properly cited and the use is non-commercial. See: http:// creativecommons.org/licenses/by-nc/4.0/

\section{REFERENCES}

1. Hoy $D$, March $L$, Brooks $P$, et al. The global burden of low back pain: estimates from the Global Burden of Disease 2010 study. Ann Rheum Dis 2014;73:968-74.

2. Hart LG, Deyo RA, Cherkin DC. Physician office visits for low back pain. Frequency, clinical evaluation, and treatment patterns from a U.S. national survey. Spine (Phila Pa 1976) 1995;20:11-19.

3. Power JD, Perruccio AV, Desmeules M, et al. Ambulatory physician care for musculoskeletal disorders in Canada. J Rheumatol 2006;33:133-9.

4. Centers for Disease Control and Prevention. National Ambulatory Medical Care Survey: 2010 Summary Tables. 2014. http://www.cdc. gov/nchs/data/ahcd/namcs_summary/2010_namcs_web_tables.pdf (accessed 31 Jan 2015).

5. Gureje O, Von Korff M, Simon GE, et al. Persistent pain and well-being: a World Health Organization study in primary care. JAMA 1998;280:147-51.

6. Cassidy JD, Carroll LJ, Cote P. The Saskatchewan health and back pain survey. The prevalence of low back pain and related disability in Saskatchewan adults. Spine (Phila Pa 1976) 1867;23:1860-6; discussion 1867.

7. Walker BF, Muller R, Grant WD. Low back pain in Australian adults: prevalence and associated disability. J Manipulative Physiol Ther 2004;27:238-44.

8. Andersson GB. Epidemiological features of chronic low-back pain. Lancet 1999;354:581-5.

9. Freburger JK, Holmes GM, Agans RP, et al. The rising prevalence of chronic low back pain. Arch Intern Med 2009;169:251-8.

10. Martin BI, Deyo RA, Mirza SK, et al. Expenditures and health status among adults with back and neck problems. JAMA 2008;299:656-64.

11. Srinivas SV, Deyo RA, Berger ZD. Application of "less is more" to low back pain. Arch Intern Med 2012 Jul 9;172:1016-20.

12. Dagenais S, Caro J, Haldeman S. A systematic review of low back pain cost of illness studies in the United States and internationally. Spine J 2008;8:8-20.

13. Lambeek LC, van Tulder MW, Swinkels IC, et al. The trend in total cost of back pain in The Netherlands in the period 2002 to 2007 Spine 2011;36:1050-8.

14. van Tulder M. Health technology assessment (HTA) increasingly important in spine research. Eur Spine J 2011;20:999.

15. Watson PJ, Main CJ, Waddell G, et al. Medically certified work loss, recurrence and costs of wage compensation for back pain: a follow-up study of the working population of Jersey. Br J Rheumatol 1998;37:82-6.

16. Luo X, Pietrobon R, Sun SX, et al. Estimates and patterns of direct health care expenditures among individuals with back pain in the United States. Spine 2004;29:79-86.

17. Koes BW, van Tulder MW, Thomas S. Diagnosis and treatment of low back pain. BMJ 2006;332:1430-4.

18. Ehrlich GE. Low back pain. Bull World Health Organ 2003;81:671-6.

19. Koes BW, van Tulder M, Lin CW, et al. An updated overview of clinical guidelines for the management of non-specific low back pain in primary care. Eur Spine J 2010;19:2075-94.

20. Fourney DR, Andersson G, Arnold PM, et al. Chronic low back pain: a heterogeneous condition with challenges for an evidence-based approach. Spine 2011;36(Suppl 21):S1-9.

21. Leboeuf-Yde C, Manniche $C$. Low back pain: time to get off the treadmill. J Manipulative Physiol Ther 2001;24:63-6.

22. Fairbank J, Gwilym SE, France JC, et al. The role of classification of chronic low back pain. Spine 2011;36(Suppl 21):S19-42.
23. Costa Lda C, Koes BW, Pransky G, et al. Primary care research priorities in low back pain: an update. Spine (Phila $P a$ 1976) 2013;38:148-56.

24. Borkan JM, Cherkin DC. An agenda for primary care research on low back pain. Spine 1996;21:2880-4.

25. Pransky G, Borkan JM, Young AE, et al. Are we making progress? The tenth international forum for primary care research on low back pain. Spine 2011;36:1608-14.

26. Kent $P$, Keating J. Do primary-care clinicians think that nonspecific low back pain is one condition? Spine 2004;29:1022-31.

27. Hall H, Mclntosh G, Boyle C. Effectiveness of a low back pain classification system. Spine J 2009;9:648-57.

28. Hill JC, Whitehurst DG, Lewis $M$, et al. Comparison of stratified primary care management for low back pain with current best practice (STarT Back): a randomised controlled trial. Lancet Lond Engl 2011;378:1560-71.

29. Foster NE, Mullis R, Hill JC, et al. Effect of stratified care for low back pain in family practice (IMPaCT Back): a prospective population-based sequential comparison. Ann Fam Med 2014;12:102-11.

30. University Health Network. Inter-professional Spine Assessment and Education Clinics. 2016. http://www.ISAEC.org

31. Saskatchewan Spine Pathway. Low Back Pain Assessment and Management Training Course. 2016. http://spinepathwaysk.ca/

32. General Practice Services Committee. Musculoskeletal Tools \& Resources. 2015. http://www.gpscbc.ca/what-we-do/professionaldevelopment/psp/modules/musculoskeletal-msk/tools-resources

33. Alleyne J, Hall H, Rampersaud R, Clinically Organized Relevant Exam (CORE) Tool for the Low Back Pain Toolkit for Primary Care Providers. Centre for Effective Practice. Funded by the Government of Ontario. 2013. ontario.ca/lowbackpain and http://www. effectivepractice.org/lowbackpain

34. Lynch ME, Campbell F, Clark AJ, et al. A systematic review of the effect of waiting for treatment for chronic pain. Pain 2008;136:97-116.

35. Wilson L, Hall H, Mclntosh $\mathrm{G}$, et al. Intertester reliability of a low back pain classification system. Spine 1999;24:248-54.

36. Sangha O, Stucki G, Liang MH, et al. The self-administered comorbidity questionnaire: a new method to assess comorbidity for clinical and health services research. Arthritis Rheum 2003;49:156-63.

37. Fairbank JC, Pynsent PB. The Oswestry Disability Index. Spine (Phila Pa 1976) 2000;25:2940-52;discussion 2952.

38. Grönblad M, Hupli M, Wennerstrand $P$, et al. Intercorrelation and test-retest reliability of the Pain Disability Index (PDI) and the Oswestry Disability Questionnaire (ODQ) and their correlation with pain intensity in low back pain patients. Clin J Pain 1993;9: 189-95.

39. Grevitt M, Khazim R, Webb J, et al. The short form-36 health survey questionnaire in Spine surgery. J Bone Joint Surg Br 1997;79:48-52.

40. Leclaire R, Blier F, Fortin L, et al. A cross-sectional study comparing the Oswestry and Roland-Morris functional disability scales in two populations of patients with low back pain of different levels of severity. Spine 1997;22:68-71.

41. Brooks R. EuroQol: the current state of play. Health Policy 1996;37:53-72.

42. Solberg TK, Olsen JA, Ingebrigtsen T, et al. Health-related quality of life assessment by the EuroQol-5D can provide cost-utility data in the field of low-back surgery. Eur Spine J 2005;14:1000-7.

43. Shaw JW, Johnson JA, Coons SJ. US valuation of the EQ-5D health states: development and testing of the D1 valuation model. Med Care 2005;43:203-20.

44. Goode AP, Carey TS, Jordan JM. Low back pain and lumbar spine osteoarthritis: how are they related? Curr Rheumatol Rep 2013;15:305.

45. Gellhorn AC, Katz JN, Suri P. Osteoarthritis of the spine: the facet joints. Nat Rev Rheumatol 2013:9:216-24.

46. Genevay S, Atlas SJ. Lumbar spinal stenosis. Best Pract Res Clin Rheumatol 2010;24:253-65.

47. Suri $P$, Rainville J, Kalichman L, et al. Does this older adult with lower extremity pain have the clinical syndrome of lumbar spinal stenosis? JAMA 2010;304:2628-36.

48. Oliveria SA, Felson DT, Reed JI, et al. Incidence of symptomatic hand, hip, and knee osteoarthritis among patients in a health maintenance organization. Arthritis Rheum 1995;38:1134-41.

49. Savage RA, Whitehouse $\mathrm{GH}$, Roberts $\mathrm{N}$. The relationship between the magnetic resonance imaging appearance of the lumbar spine and low back pain, age and occupation in males. Eur Spine $J$ 1997;6:106-14.

50. Garstang SV, Stitik TP. Osteoarthritis: epidemiology, risk factors, and pathophysiology. Am J Phys Med Rehabil 2006 quiz S12-4;85: S2-11. 
51. Kalichman L, Li L, Kim DH, et al. Facet joint osteoarthritis and low back pain in the community-based population. Spine (Phila Pa 1976) 2008;33:2560-5.

52. Prieto-Alhambra D, Judge A, Javaid MK, et al. Incidence and risk factors for clinically diagnosed knee, hip and hand osteoarthritis: influences of age, gender and osteoarthritis affecting other joints. Ann Rheum Dis 2014;73:1659-64.

53. Kadam UT, Jordan K, Croft PR. Clinical comorbidity in patients with osteoarthritis: a case-control study of general practice consulters in England and Wales. Ann Rheum Dis 2004;63:408-14.

54. Gandhi R, Woo KM, Zywiel MG, et al. Metabolic syndrome increases the prevalence of spine osteoarthritis. Orthop Surg 2014 ;6:23-7.

55. Schellevis FG, van der Velden J, van de Lisdonk E, et al. Comorbidity of chronic diseases in general practice. J Clin Epidemiol 1993;46:469-73.

56. Cushnaghan J, Dieppe P. Study of 500 patients with limb joint osteoarthritis. I. Analysis by age, sex, and distribution of symptomatic joint sites. Ann Rheum Dis 1991;50:8-13.

57. Srikanth VK, Fryer JL, Zhai G, et al. A meta-analysis of sex differences prevalence, incidence and severity of osteoarthritis. Osteoarthr Cartil 2005;13:769-81.

58. Duncan AE, Colman RJ, Kramer PA. Sex differences in spinal osteoarthritis in humans and rhesus monkeys (Macaca mulatta). Spine (Phila Pa 1976) 2012;37:915-22.

59. Suri P, Miyakoshi A, Hunter DJ, et al. Does lumbar spinal degeneration begin with the anterior structures? A study of the observed epidemiology in a community-based population. BMC Musculoskelet Disord 2011;12:202.

60. Suri P, Hunter DJ, Rainville J, et al. Presence and extent of severe facet joint osteoarthritis are associated with back pain in older adults. Osteoarthr Cartil 2013;21:1199-206.

61. Kjaer P, Leboeuf-Yde C, Korsholm L, et al. Magnetic resonance imaging and low back pain in adults: a diagnostic imaging study of 40-year-old men and women. Spine (Phila Pa 1976) 2005;30:1173-80.

62. Konstantinou K, Hider SL, Jordan JL, et al. The impact of low back-related leg pain on outcomes as compared with low back pain alone: a systematic review of the literature. Clin J Pain 2013;29:644-54.

63. Deyo RA, Dworkin SF, Amtmann D, et al. Focus article: report of the NIH task force on research standards for chronic low back pain. Eur Spine J 2014;23:2028-45.

64. Busse JW, Riva JJ, Nash JV, et al. Surgeon attitudes toward nonphysician screening of low back or low back-related leg pain patients referred for surgical assessment: A survey of Canadian spine surgeons. Spine (Phila Pa 1976) 2013;38:E402-8.

65. Busse JW, Riva JJ, Rampersaud R, et al. Spine surgeons' requirements for imaging at the time of referral: a survey of Canadian spine surgeons. Can J Surg 2014;57:E25-30.

66. MacKay C, Davis AM, Mahomed NN, et al. A single group follow-up study of non-surgical patients seen by physiotherapists working in expanded roles in orthopaedic departments: recall of recommendations, change in exercise and self-efficacy. BMC Res Notes 2012;5:669.

67. Petersen $\mathrm{T}$, Laslett $\mathrm{M}$, Thorsen $\mathrm{H}$, et al. Diagnostic classification of non-specific low back pain. A new system integrating patho-anatomic and clinical categories. Physiother Theory Pract 2003;19:213-37.

68. Petersen T, Kryger P, Ekdahl C, et al. The effect of McKenzie therapy as compared with that of intensive strengthening training for the treatment of patients with subacute or chronic low back pain: a randomized controlled trial. Spine (Phila Pa 1976) 2002;27:1702-9.

69. Brennan GP, Fritz JM, Hunter SJ, et al. Identifying subgroups of patients with acute/subacute "nonspecific" low back pain: results of a randomized clinical trial. Spine 2006;31:623-31.

70. Lemeunier N, Leboeuf-Yde C, Gagey O. The natural course of low back pain: a systematic critical literature review. Chiropr Man Therap 2012;20:33

71. Itz CJ, Geurts JW, van Kleef M, et al. Clinical course of non-specific low back pain: a systematic review of prospective cohort studies set in primary care. Eur J Pain 2013;17:5-15.

72. Greenough CG, Fraser RD. Aetiology, diagnosis and treatment of low back pain. Eur Spine J 1994;3:22-7.

73. Balagué $F$, Mannion AF, Pellisé $F$, et al. Non-specific low back pain. Lancet 2012;379:482-91. 